\title{
Inclusive Innovation in the Private Sector: The Case of East African Technology Start-Ups
}

\author{
Kari Koskinen \\ London School of Economics and Political Science \\ k.m.koskinen@1se.ac.uk
}

\begin{abstract}
Inclusive innovation argues for the inclusion of societally marginalised groups into the innovation process in order for them to better benefit from the innovations. In the literature on the topic, the main actors behind these innovations are multinational enterprises or entities from the public or third sector. However, in a developing country context, inclusive innovation might be equally relevant for small private sector entities, as they often target the same users, for example the non-profit sector.

This paper studies the role of inclusive innovation in technology start-ups in East Africa and argues that, despite their profit seeking purpose, contextual factors force many of these start-ups to automatically adopt methods advocated by inclusive innovation. This has important implications to evaluating the role of the private sector as a provider of services and products that can be seen as having a positive impact on the lives of these groups.
\end{abstract}

\section{Introduction}

The high growth rates in mobile phone ownership and expanding network coverage a in large number of developing countries has paved the way for innovations based on information technology (IT). These innovations are seen as important tools in helping to solve societal and other problems that many of these countries face. Over the past decades this has led to a rise in the number of projects and initiatives that are based on the usage of digital technologies with an aim to improve quality of life in these countries. However, their success has been questionable, and although it is not always straightforward to determine when a particular project can be declared as a failure or a success, the general view seems to suggest that many of these IT projects and innovations end up failing either completely or partially [1-3].

One reason that has been given for the high failure rates are the so-called design-reality gaps. These gaps are the results of systems that are based on innovations designed in locations that are geographically and contextually very different from the ones where the innovations will be used. As a consequence, the requirements for these innovations to work as intended in the design stage are not met in the implementation location [2, 4]. Moreover, in relation to development studies, it does not automatically follow that any innovation, technological or otherwise, can be seen as beneficial from a developmental perspective. In the case of innovations, they do not necessarily target groups that find themselves marginalised or otherwise excluded from society, such as the poor, and even when they do, the societal and other contextual factors of the marginalised group are not really understood by the innovator in the first instance. This has given rise to the notion of inclusive innovation, which aims to involve the targeted marginalised groups into the innovation process, and by doing so make the innovations more sustainable and relevant for these groups [5].

Design-reality gaps and inclusive innovation both argue for the importance of understanding the contextual requirements that are relevant in the location where an innovation or IT system is to be implemented. If these and actual users of the innovation are not taken into account and included into the innovation process, the chances of the innovation not meeting its objectives are likely to increase. One rather clear solution for this is therefore to take the design and development of these innovations and systems closer to the area and context where they will be used. The problem, however, is that for many technological innovations, this requires a lot of investment and resources that may not be readily available in the implementation location.

Software and application development provides an interesting exception in this sense. Especially in the case of small scale local innovation and systems development, most of the technological and other resources needed in the process can be transferred from one location to another with relative ease over the internet. Examples of these are application programming interfaces (APIs) and software development kits (SDKs), but also much of the material needed for training or technological problem solving can be found from the web. Although these resources usually originate from developed countries and therefore come with the risk of not fitting the local context in developing countries, they also possess high levels of generativity [6], enabling the reshaping of these resources into applications that at least in principle 
can match the needs and wants of the local users. Hanseth's and Lyytinen's description of applications highlights this and also resonates with some of the ideas behind inclusive innovation: 'applications consist of suites of IT capabilities. They are developed to meet a set of specified user needs within a select set of communities.[...] An application is a priori determined by choice of design context, user groups and functional goals' [7].

In summary, application development as such has the potential to bring the innovation process closer to the locations where they are to be used. This links to the notions of inclusive innovation. Its relevance is generally recognised and accepted as a guideline for actors working in the field of development studies, but the research on the topic has concentrated more on the non-profit sector, such as aid organizations and large multinationals [8]. This paper approaches inclusive innovation from the perspective of the local private sector, namely small technology businesses. It studies whether locality leads private companies to somewhat automatically adopt processes that result in the inclusion of the type of marginalised user groups that inclusive innovation refers to into the design phase of the applications. The main research question is how inclusive are technology start-ups based in developing countries in their functioning and what are the mechanisms behind it?

In the literature, requests have been made to investigate what type of organizations initiate inclusive innovation [9]. Due to their locality, small businesses should be in good position to understand the local context and to adopt some of the guidelines of inclusive innovation into their functioning. Whether this actually happens is another matter, as it can be argued that they have no incentives of doing so because the main motivation for a private company is to make profits and not so much contribute to the general development of a society. However, if these start-ups can be seen as inclusive, they at the very least do then have an impact to the lives of the marginalised groups, which raises further questions on their exact developmental role regarding these groups.

The paper is organised in the following manner: first it looks at the relevant literature on the topic. Then it moves onto framing the research and introduces the methodological decisions taken for data collection and analysis. Then, it discusses the results of the analysis and their implications to the research area. Final chapter concludes.

\section{On Inclusive Innovation}

The notion of bringing software development closer to the location of implementation is rooted in the idea of design-reality gaps. Heeks sees that these gaps are the result of the contextual and other differences that exist between the design and usage location of an IT system or innovation [4]. Overall, design-reality gaps may occur in different areas of IT system development and implementation, for example in relation to technology, processes or skills. In a similar vein, gaps can also take place in the form of expectations, which is what happens if the implemented system or innovation is unsuccessful in meeting the specific goals set to it in the design phase [10].

Taking the design and development phase of the systems and innovations closer to the areas where they are to be implemented enables closer interaction with the intended users. This also resonates with the ideas behind inclusive innovation. The main aim of inclusive innovation, according to the current understanding, is to get innovators to involve relevant institutions and stakeholders into the design phase of an information system or IT innovation [11]. The underlying reasoning is that groups, of which the system or innovation is dependent on in its functioning, need to be involved in designing them. In the field of development studies, the groups that need to be included are the ones that find themselves marginalised in the society, such as the poor.

Overall, inclusive innovation can be seen as a tool to incorporate the normally excluded groups into the innovation process and, as a result, enable these groups to enjoy the benefits of the innovation. George et al. define inclusive innovation as "the development and implementation of new ideas which aspire to create opportunities that enhance social and economic wellbeing for disenfranchised members of society" [9 $\mathrm{p}$. 663]. In addition to increased incomes, inclusive innovation can benefit marginalised members of a society, for example through capacity building [12]. In the developing country context, inclusive innovation has been seen as a way of integrating especially the poor into markets [13]. On a more systemic level, innovation is seen as vital for developing countries to move away from pure primary production to more valuable sectors of economy. By making the innovations that are needed for this shift in an inclusive manner, it is hoped that then also the benefits will reach larger numbers of members of the society [14].

Inclusive innovation shares common characteristics with user-inclusive innovation $[15,16]$. User-inclusive innovation enables joint action between the key stakeholders and groups, which leads to collective meaning-creation, knowledge-sharing and alignment of interests between the relevant parties. As a result, the producers can create products, services and systems that would better match the needs and wants of the users. Within development studies, inclusive innovation is closely linked to the idea of what kind of developmental benefit an innovation can bring for the targeted group. Views differ however on what is meant with inclusiveness, as well as on when an innovation is considered truly inclusive. A rather narrow interpretation of inclusive innovation has traditionally been one where inclusivity is understood as a capability to turn the marginalised group into either consumers or the workforce producing the innovation $[15,17]$. This 
type of inclusion does not yet mean letting the marginalised group participate in the actual design phase of an artefact or service; the inclusiveness stems from providing the group purchasable products or work opportunities that can lead to increased income levels and skill creation.

This type of inclusiveness has been referred to as liberal definition of inclusive innovation [18]. For Papaioannou, inclusive innovation should be understood more broadly and defines the concept in terms of participation and equity. Participation means that all the necessary stakeholders must participate in the design phase. Equity on the other hand stands for the need to make sure that the result of the innovation serves the entire targeted group and not just some segments of it. Cozzens and Sutz follow a similar logic and state that an innovation of this type must be inclusive regarding the process and the problems it aims to address. The marginalised group must participate in the design and development process, as well as take part in defining the problems and solutions that the innovation seeks to address [19].

This broader understanding of inclusive innovation has as its objective to produce more relevant and sustainable innovations and projects for the targeted groups. User participation in the innovation process is believed to help to avoid many of the pitfalls present in the innovation process. Furthermore, the narrower the geographical and cultural distances between the innovators and the targeted users, the more likely the innovation is to meet its objectives, as it is claimed that the key for success regarding any innovation is the interaction between intended users and producers of the innovation [20-22].

Therefore, inclusive innovation should be seen as a collective process where the intended users can educate the entities driving the innovation of the realities that the users face and how those realities might affect the solving of the problems that the innovation aims to address [19]. The members of the included group should be seen as agents and not as patients that need to be treated. Swaans et al. talk of innovation platforms, which are spaces that enable the incorporation of the marginalised and other relevant groups into the innovation processes [23]. In general, the need for interaction seems to be commonly agreed. How much inclusiveness is needed in an innovation and how it should be done, however, has remained less clear.

Heeks et al. respond to this by stating that an innovation can have different levels of inclusiveness [5]. They introduce a tool that helps to evaluate how inclusive an innovation or innovation process is and see this tool as a six step ladder, where each step is incremental to the one below it. These ladder steps are labelled as: intention, consumption, impact, process, structure and post-structure. Starting from the first and most basic level, innovation can be considered inclusive in intention if the objective of the innovation is to address issues that are relevant to the group that needs to be included. Intention does not mean, however, that any concrete action is taken to actually include the targeted group into the innovation process, or that the group will use the innovation. The next step, consumption, therefore takes a step further by setting an additional requirement that for an innovation to be inclusive at the second level it should also be adopted and used by the included group. The third step, impact, states that the innovation must furthermore have a positive impact for the group. If an innovation is used but does not bring any benefits to the group, then the innovation cannot be considered inclusive in terms of impact.

Only the fourth step, process, points towards the more holistic definition of inclusive innovation and argues for the need to have the targeted group incorporated into the innovation process. This type of inclusion may take place at any stage, starting from the design phase all the way to the innovation's distribution, or somewhere in between. Also the depth of participation varies and ranges from being informed to actively participating in the process and controlling it. The fifth step, structure, incorporates the system level to the ladder by stating that an innovation needs to be created within an innovation system where the underlying institutions, organizations and relations between the key stakeholders are themselves inclusive. If this is not the case, the risk is that the inclusive processes remain temporary or shallow in their achievements. Finally, the last step in the inclusiveness ladder, post-structure, maintains that an innovation must be created in a setting that allows the knowledge and discourse frames to be inclusive within themselves. The framing of the main actors and stakeholders must be done so that the targeted group gets to say who should be involved. If this is not the case, the innovation cannot be considered inclusive from a post-structural perspective.

When the discussion turns to the role of companies in inclusive innovation, criticism has been expressed towards viewing the poor as primarily consumers, as described by Prahalad [17]. Furthermore, it has been argued there has also been inability from the part of the companies to understand how inclusive innovation differs from other business initiatives and innovation processes [24]. Regarding the user side, the creative capacity of the marginalised groups as well as their general interest towards entrepreneurship have been questioned [25]. Overall, it could be argued that the capacity of businesses to adopt inclusive innovation approaches has been considered as somewhat questionable.

However, there are two reasons why this type of view might not be entirely accurate. First, the notion of including users into the design phase is relevant also for innovations that ultimately have an economic goal in terms of creating profits for the businesses. Second, particularly small companies in developing countries can be found from the areas that 
inclusive innovation aims to target, where lot of the economic activities take place within the informal economy. Although the formal and informal sectors are often interlinked, especially when it comes to the exchange of goods and services, it is estimated that for example in many Sub-Saharan countries the informal sector forms more than 70 percent of their economy [26]. Many companies in developing countries need to be in connection with the informal economy, which means that they are likely to be relatively well aware of the societal challenges of the groups that get their living from the informal economy.

Therefore, entrepreneurs working within the informal sector may target many of the marginalised groups that the formal economy does not necessarily reach. These entrepreneurs and small companies may be capable and well-positioned in bringing products and services that meet the needs and available economic and other resources of the marginalised groups. Among these enterprises there exists considerable heterogeneity though, as some of them are more connected to the formal sector than others, and these companies also differ in terms of what they produce or skills and other resources they possess [26-28]. Thus it cannot be directly concluded that all the informal sector small businesses would somehow be automatically userinclusive, but the potential for this exists. Overall, the question on how inclusive companies are is believed to be linked also to their size, and calls have been made for further research regarding this aspect [9].

\section{The Contextual Factors in Application Development}

Development is often seen as a concept that entails betterment of certain aspects. Different theories give different interpretations on what development means and what exactly needs to be developed in order for a country to thrive and become developed [29]. However, at the same time, development as an idea presupposes a developmental setting for the whole society. If a country or an area is considered a developing one, there needs to exist also certain societal or other factors that cause this. These factors can be issues such as high illiteracy or child mortality rates, lack of clean water or food, to mention a few. Either way, the same reasons that lead a country or a region to be called a developing one also form a certain kind of context. When a company works in this type of context, it should also be also betterpositioned to understand the conditions that this type of developmental context poses on the lives of the targeted users.

Schumpeter famously stated that inventing a new product or process provides a firm a competitive edge [30]. However, invention became an innovation only after it was transferred from an idea into practice. An innovation can be a force of change, but in order for it to succeed it has to be also gain traction among its targeted users. The technology start-ups that operate in a developing country and aim to create products and services for the local markets can be seen as trying to invent solutions to the untapped needs and wants of their targeted users the entrepreneurs have perceived in the surrounding society.

The development of software and application provides an interesting case of an innovation that takes technological resources that have their origins elsewhere but assembles them in a way that fits the local context. The innovation processes of digital technology are in this sense both distributed and combinatorial [31]. They can be distributed geographically as well as across different actors and resources. At the same time, the technological essence of application development is the ability of the developers to combine these resources that as such are often external to the application itself, as is the case with the APIs and also with the SDKs that are used to build the applications.

In other words, from a technological perspective, any resource that can be digitized has the potential to become ubiquitous in terms of being available everywhere and at any time to anyone with an internet connection. This leads to a certain type of decontextualization of these technological resources, as they get carried from one place to another and utilized in different ways in different contexts [32]. These resources function as toolkits that enable the transfer of application creation capabilities from the platform owners to the third-party developers [33]. In this sense these resources get re-contextualised when they are being put into use according to the needs and wants of the local developers.

However, the context, where the development of these applications occurs, places limitations on what can or cannot be done. As noted by Karippacheril et al. [34] regarding the usage of mobiles and application development in developing countries, there are certain structural obstacles that may hinder the inclusiveness of the targeted users, such as the cost of mobile services, SMS and data. Also device centric platforms are hindered by lack of access to infrastructure and connectivity for economically poor users, and due to the need to provide affordable access platforms are typically based on SMS or cheap feature phones. On the usability side, issues such as technical literacy and lack of trust towards the mobile as an information channel as well as local content may restrict adoption. The technology start-ups that build applications for local markets and target the for example the poor must found ways to overcome these obstacles in order to succeed. One way to do this is to include the users into the development process of the application.

The six-step ladder presented by Heeks et al. functions as a tool to estimate how inclusive are the innovations of technology start-ups that operate in a developing country context. These start-ups form an interesting case in a sense that they are local, thus being in close physical proximity to the targeted user groups. However, they use and rely on resources such as 
software development kits (SDKs), application programming interfaces (APIs) and hardware that in most cases come from other countries and contexts, both in terms of distance but also in terms of societal and cultural factors.

\section{Methods}

To answer the research question, qualitative methods were used as they allowed more room for the developers to express their views and describe the different nuances in more detail than for example quantitative methods in the form of surveys. The findings are based on 25 interviews mainly with application developers but also with other relevant actors, such as technology hub managers located in the region of East Africa. The length of the interviews ranged from 30 minutes to one hour and 15 minutes, on average lasting approximately 45 minutes. The interviews were semi-structured, where questions aimed to capture the lifespan of the applications and start-ups starting from the idea behind the applications to the current situation. Emphasis was given to interview questions that dealt with the challenges the start-ups had faced, user engagement activities, or to the way the application itself had evolved and changed during its development.

To complement the interviews and also to verify some of the claims made by the developers, additional data was gathered from participation at start-ups pitching events in Nairobi (Kenya) and Kampala (Uganda), from discussions with members of different start-ups based in East Africa, as well as from spending time on two different technology hubs in Kampala and performing participant observation. Furthermore, informal discussions were conducted with people belonging to intended user groups in order to find out their opinions on the applications. Overall, the main bulk of the data was collected from companies and relevant actors operating in Kampala, Uganda.

The interviews were recorded and transcribed. Notes were also taken from the informal talks with the intended users and relevant stakeholders, as well as from the participant observation that took place in the technology hubs. The data was analysed by using thematic analysis. Themes that rose from the data and that were relevant for this research were ones where notions to inclusive innovation were made, such as how to target users, ways to include the users to development and barriers to participation. Content analysis might also have been a suitable method by using Heeks' ladder as a starting point, but it was considered that thematic analysis enabled the analysis to have more depth as it did not tie the data to ready-made categories right from the start. However as mentioned previously notions related to inclusive innovation did provide a basis for data analysis after creating the themes from the data. The relevant themes were then linked to Heeks' steps in the inclusive innovation ladder. In the following, the results of the analysis will be presented by going through one step at a time, after which discussion will follow based on the findings.

\section{Results}

The main driver behind most of these start-ups is to generate income. As always, this can be obtained by receiving investments or getting users to pay for the product or service. Although for example Uganda scores very high on levels of entrepreneurship [35], the respondents stated that there are very few investors or funding available for the start-ups, and as a result, most of them had to rely either on their own financial resources or alternatively create applications that will almost immediately generate income for the start-up. Options that work in more developed markets, such as first creating a large enough user-base without actually generating any income from the service or product, were not seen as viable. In general, the start-ups often held the view that not too many users were willing to pay for the apps alone, which meant that the start-ups had to tap into already existing financial flows, i.e. to areas of services and products where people were already accustomed to paying, and get their cut from these financial streams. This on the other hand had important consequences in relation to the six steps of inclusive innovation, which shall be analysed next.

\subsection{Intention}

The question of whether there exists an intention behind the application to reach and benefit groups such as poor depends partly on definition. In a society where many are considered poor, someone who within that particular society is considered relatively wealthy, might not actually be so if compared to other societies. Furthermore, as the share of the population that enjoys a higher income is relatively low, in order to gain a large amount of users it makes more sense to target groups that might not have much income but are big in numbers. However, as noted above, the start-ups do have to also target existing flows of money, which means that there is a limit to how poor the users can be, or as one entrepreneur stated, "there is a bottom to the bottom of the pyramid market".

Overall, it is sometimes difficult to judge whether there is inclusiveness regarding intention. In the case of platforms that have users from different user groups, it might be that one user group can be considered economically well off but the other not, and the app would help the latter to make more money. For example, a laundry app that connects people who need to have their laundry done with washers, the former cannot really be considered poor, since otherwise they would do their laundry themselves. However, the people who do the laundry were mostly women with a low income. A slightly different example was a case of an app that aimed to provide its users safe motorcycle taxis. While 
many of the users of the app could be considered forming a part of the population that had at least some income, the same was not necessarily true for the motorcycle taxi drivers. At the same time, they were not generally considered within the society as being extremely poor, but on the other hand could not be seen as wealthy either. Thus, the question is also where to draw the limits on what constitutes as excluded, for example in terms of being economically poor.

This pattern was seen across other applications as well, were they about providing information related to agriculture to farmers or connecting or providing cheaper ways to do ultrasound in rural areas. Although not all the stakeholders were necessarily poor or excluded in some aspect, some of the benefits of those applications were meant to fall on groups that could be considered marginalised. In general, only in a few cases was it relatively clear that the intention was not there to reach out to marginalised groups in any way. This was the case for example regarding game apps or start-ups that concentrated on creating websites for other companies. Regarding the other apps that were more inclusive in intention, they often needed to connect with wider array of stakeholders, and out of those at least some of them could be seen as poor or otherwise marginalised.

\subsection{Consumption}

Since many of the companies interviewed and studied were only about to start their businesses it was difficult to conclude how widely their products and services were used. For companies that had existed for some time, there were signs that their products were also used by their target audiences. Similar to intention, the question in some of these cases was whether these groups qualify as marginalised.

However, there were a number of potential obstacles for adoption and consumption, many of which were technological and the kind mentioned by Karippacheril et al. [34], such as ownership of suitable devices among the targeted group. These obstacles forced the entrepreneurs to think of ways to bypass them in order to guarantee consumption. This was done for example by providing microloans for the targeted users so that they could buy themselves smartphones that were needed to use the application, or then building the application in a way that it was less data-intensive or could be used with a basic phone. Regarding digital literacy some applications functioned via middlemen, who then passed the relevant information to the targeted users such as farmers.

Overall, the start-ups seemed to foster relatively close contacts with the targeted users in order to make their products not only relevant but also accessible. As an example, some of the measures to bypass the obstacles for adoption mentioned above were the result of this type of interaction between users and the start- ups, and had taken place after launching the first version of the applications.

\subsection{Impact}

As impact requires some level of consumption and it was difficult to estimate this, also inclusiveness in terms of impact was less clear. However, there were some indications that especially applications that functioned as platforms were bringing benefits in the form of increased incomes for the user group that could be considered marginalised, as in the case of the washers in the case of the laundry app. Despite these weak signals, for most applications it was too early to draw conclusions about their overall impact, although some pilot testing had shown positive results in this sense. Furthermore, some start-ups simply did not last long enough to have much impact.

On a slightly different note, the overall process of creating the start-ups themselves had had a positive impact for the entrepreneurs in terms of work opportunities, skills learning and in few cases higher income. However, it is questionable whether this group could be seen as marginalised in any meaningful way, especially if compared to the rest of the society.

\subsection{Process}

In some cases, the start-ups did initial studies on the markets and tried to reach out to the intended users to make sure there was general interest towards the application. Sometimes this also included interviewing the users on what they would like to have in the application. However, there were also quite often cases where the first versions of the applications were not necessarily built in a way that included the targeted users, and no pre-release research on the market was done. This occurred especially if the application was initially born as a result of a hackathon or a simple idea that one of the developers had thought of. However, after having built the first version, the interaction that took place between the start-up and its intended users often increased significantly, and there were also comments on how the companies where moving away from identifying themselves as technology companies but becoming more and more social in a certain way. One developer commented that "it has been ages that I have done any of that tech stuff, nowadays I am just all the time calling to the customers and asking if they have liked the service". A co-founder of another company stated that "the app is actually just a very small part of the business". There were also implications that this interaction with the users had also led to changes either for the application or other initiated processes that helped to attract the users.

In general, inclusion within the process was limited largely to giving feedback on the application, and did not mean that the groups to be included were made part of the start-up in some way. Also as noted above, the 
people who worked in these start-ups were not from a particularly poor background.

\subsection{Structure}

As the fifth step in Heeks' et al. ladder explains, in order for an innovation to be inclusive it needs to happen in a structure where the different actors and institutions are inclusive themselves. In case the group that needs to be included are the poor, one way to look at this is in terms of costs of forming part of the relevant institutions. In terms of tertiary education, many of the entrepreneurs had a background either in engineering or business studies. In Kampala for example, annual tuition fees in the local Makerere University for those degrees are around 300-400 dollars at the time of writing [36], and the average gross national income per capita in 2014 was at 670 dollars [37]. Without external funding many might not afford the education that many of the entrepreneurs had.

In relation to the companies themselves, many of them resided in the technology hubs. Some hubs were free for the start-ups but not all. One hub in Kampala asked the start-ups to pay a monthly fee of slightly under 30 dollars. Overall, not much external funding was available for the start-ups in the form of investors in Kampala, although the situation was somewhat different in Nairobi. Most of the external funding came in the form of competitions, where the winner was able to win funding usually worth a few thousand dollars at maximum. Winning a competition however also came with a cost, because although they gave the start-ups financial and other type of resources, it sometimes also came with certain conditions, such as that the application had to be developed to work in a certain operating system or to use certain resources provided by the organizing entity. This did not necessarily make sense in terms of the targeted users, for example in case the operating system was not widely adopted by the users. In relation to the technological resources, the structural factors were more inclusive from the perspective of the tools that were needed to build the application such as SDKs and APIs. However, this inclusiveness was balanced out by the costs of acquiring the hardware, which was out of reach for many, especially when considering the high shipping costs to countries like Uganda.

Overall, it could be argued that due to the general low average income in these areas, the structure could not be claimed to be very inclusive. However, as it often happened that in the process the development of the applications started to have more social aspects, and in this sense became less technological, the targeted user groups were involved in the developing process of the applications as the developers wanted to know their thoughts and opinions of the application. It is questionable though if this can be seen as evidence of inclusiveness in structure. The marginalised group had a role as possible users, but the structure also inhibited them from becoming developers or entrepreneurs themselves. That would have required, among other things, access to the educational institutions, which demanded resources and skills that many in the marginalised group simply did not have. The structure did not therefore enable them to have a role that would have gone beyond one of giving opinions on how the application should be developed.

\subsection{Post-structure}

The last step in the ladder is post-structure, and it states that the innovation setting has to allow inclusive knowledge and discourse frames, and the included group should have a say which stakeholders and main actors should be involved. Unless in the relatively unlikely event that the excluded group created the startup, this did not occur, and there were not any instances where the founders of the start-up could really be seen as being part of any marginalised group. However, as with other steps, the question of the inclusiveness on the post-structural level is not entirely clear since although many of the developers can be considered as being better off than many others in the society, it can be asked how much of that is applicable when compared to other societies.

\section{Discussion}

The summaries of the results from the analysis are described in table 1. As the table also shows, the higher steps of the inclusiveness ladder were not really met or seen among the start-ups and applications studied.

Overall, due to the relatively close physical proximity between the targeted users and the start-ups, the developers were more aware of the contextual factors that existed in the locations and were relevant for the application development. If the application relied on a marginalised group in its functioning, it had to make sure that the application was accessible to that group, which meant that interaction with that particular group was necessary. This became relatively visible for example in the technological contextual factors that the start-ups needed to overcome, such as making their application usable in devices that were not too expensive or changing the way it functioned so that it was relatively easy to use.

Regarding inclusive innovation, some of the steps in Heeks' et al. ladder seemed to take place almost automatically for technology start-ups in East Africa, such as the ones related to process. Furthermore, the start-ups did not necessarily follow the ladder in the sense that one step was a necessary condition for the next one. In some cases, the start-up scored relatively well, for example regarding process or consumption, but did less well in terms of impact or intention. Although the evidence on this was in some cases limited due to the newness of many of the applications, this could be at least partly due to the unpredictability of the usage 
patterns of an application, as it can be difficult to estimate beforehand who exactly is going to use the application (and how) in the initial stages of the application development. The issue that did remain relatively clear though in terms of structure or poststructure: the start-ups did not do too well in reaching the higher steps of the inclusive innovation ladder, something which was more a system level issue and was related to the general societal factors and not so much for the start-ups themselves.

\section{Table 1. Results from the Data Analysis}

\begin{tabular}{|l|l|}
\hline Area & Results \\
\hline Intention & $\begin{array}{l}\text { Many applications targeted user } \\
\text { groups that could be considered } \\
\text { marginalised. }\end{array}$ \\
\hline Consumption & $\begin{array}{l}\text { Some evidence that applications } \\
\text { were also consumed by the } \\
\text { marginalised user groups. }\end{array}$ \\
\hline Impact & $\begin{array}{l}\text { In most cases too early to say as } \\
\text { consumption was still low, however } \\
\text { especially applications that } \\
\text { functioned as platforms had } \\
\text { generated some impact as well in } \\
\text { terms of increased incomes. }\end{array}$ \\
\hline Process & $\begin{array}{l}\text { Targeted user groups were in some } \\
\text { cases included in the process in the } \\
\text { form of giving feedback of the } \\
\text { application, but not for example as } \\
\text { owners or employees of the start- } \\
\text { ups. }\end{array}$ \\
\hline Post-Structure & $\begin{array}{l}\text { The obstacles for marginalised } \\
\text { members of the society were quite } \\
\text { considerable for example in terms } \\
\text { of the cost of education, and } \\
\text { therefore the overall structure could } \\
\text { not be seen as very inclusive. }\end{array}$ \\
\hline Structure & $\begin{array}{l}\text { No evidence of inclusiveness. } \\
\text { Tans }\end{array}$ \\
\hline
\end{tabular}

Overall, the question of inclusive innovation has a lot to do with what is meant with marginalised groups, or how to define a group that needs to be included. If the aim is to include poor, then it must also be defined what constitutes as poor. Furthermore, if the business plan of a company is to get incomes directly from its users, there are limits on which groups a profit-seeking company may target. However, as seen in the case of platforms, this does not mean automatically that the marginalised groups could not be one of the key stakeholders that the application developers have to take into account and include in the innovation process. Including a marginalised group in the process might require changes to the technologies that are used and to the ways applications are built, so the technologies have to be adapted in a manner that fits the target group that needs to be included.
The developmental impact that these applications were aiming to deliver for the marginalised groups meant usually higher incomes or increased earning opportunities. There were some instances where other developmental aspects such as improved maternal healthcare also played a role, but those were not too many. In this sense it seemed that although the start-ups were able to fulfil some of the aspects of inclusive innovation, their impact was mostly economic. It might be an exaggeration to conclude that private enterprises can only deliver economic benefits to marginalised groups, but this was often the case regarding most of the start-ups that could be seen as having any type of a developmental impact.

As a consequence, the start-ups' association with inclusive innovation seems to be closely linked to their intention to generate profits. In an area where the overall income levels are generally low for most part of the population, most of the companies seek to tap into already existing financial flows, which in practice is done by providing services and products that people are already accustomed to paying for. In some cases this also meant that the companies present themselves as middlemen, who tune the existing practices in a manner that from their point of view brings benefits to the users but also to themselves in terms of revenue.

Overall, since financial resources for these companies are scarce, most of them need to start generating revenue straight away. Because of this need to make money right from the start, most of the start-ups are in a certain sense forced to become inclusive towards the groups whose needs they aim to address. If the targeted group is defined as marginalized in some respect, then by the necessity to understand better the needs and wants of the targeted user group the companies automatically include ways of functioning that have elements of inclusive innovation in them, such as intention, consumption and process. This is further intensified by the gradual transformation of many of the start-ups from pure technology start-ups, where the main aim is to build the applications, towards entities that become more aware of the importance of understanding the social factors that affect their users.

The inclusive innovation of these start-ups seems to stem from the general context where they operate in. There is a risk that as soon as general income levels rise in a certain area, the start-ups are more likely to target users that are better off and have financial resources to pay for the services that the companies provide. In this case the aspects of inclusive innovation that can now be found from the start-ups may disappear. The inclusive innovation factors are thus present in these start-ups only because there is often no other choice: if they wish their products and services to reach a wide number of users in a country where many can be considered poor, there are not too many other user groups they can target. When and if the amount of people that can be seen as relatively wealthy increases, it becomes more attractive for the start-ups to build services and products for them, 
since there is more money to be made around these target groups than in the poorer segments of the society. Moreover, it can be easier to target groups that are in possession of devices that are developed enough to use the full spectrum of possibilities offered by the technological resources and are also accustomed users of more advanced phones. This can also lead to additional cost savings, as the start-up does not have to tailor their application and business plans to also work for users that have limited technological skills and devices that can also do very basic functionalities.

The fact that the start-ups were not too inclusive in terms of structure and post-structure points more to the direction of the overall innovation system of a particular country or area. There is not much the individual startups can do to correct this, but it more stresses the role of public sector and governments in creating innovation environments, where inclusiveness reaches the level where marginalised groups can be more than just users of innovations, and having also access to the skills and resources that are needed in establishing and successfully running start-ups. In short, the start-ups may have a role in bringing betterment to the marginalised groups, but in order to create more equal opportunities for all the segments of the society, a holistic approach that includes all the different sectors of the society has to be taken.

As a final note regarding the findings on this paper, there are some important limitations that should be taken into account. Firstly, as noted the data is mainly collected from Kampala, which in itself differs from other cities and areas in the region. To have a more thorough understanding of how much the findings apply to other places in the region, more data would be needed from those regions. Further research could be conducted by studying more developed areas and looking into how many of the applications and start-ups target users that can be seen as marginally excluded.

Secondly, although a saturation point was achieved regarding the interviews, i.e. many of the developers mentioned similar issues relevant for the research, the research would also benefit from additional interviews from Kampala that would be made conducted with companies that are bigger than start-ups, as it would further strengthen the arguments this paper aims to make.

\section{Conclusion}

Inclusive innovation is seen as a way to innovate in a manner that brings developmental benefits to groups that are otherwise marginalised in society. Often seen as something that has to be actively advocated to different entities working in developing countries, this paper has shown that regarding small technology businesses, some of the aspects of inclusive innovation occur automatically given that the general societal context fulfils certain requirements. However, the start-ups adopted methods of inclusive innovation not necessarily out of choice, but more due to the existing contextual factors that left very little room for them to work in another manner, and therefore may stop doing so if conditions change. This can possibly be avoided by creating an environment where the overall innovation structure is more inclusive so that it allows the marginalised groups themselves to have a more active role in creating these enterprises. That, on the other hand, depends on the policies at the state level, highlighting the important role that the public sector has in enabling the type of inclusive innovation that includes all of the steps of the inclusiveness ladder.

\section{References}

[1] L. Dodson, S. R. Sterling, and J. K. Bennett, "Considering Failure: Eight Years of ITID Research," Information Technologies \& International Development, vol. 9, no. 2, pp. pp. 19-34, Jun. 2013.

[2] R. Heeks, "Health Information Systems: Failure, Success And Improvisation," International Journal of Medical Informatics, vol. 75, no. 2, pp. 125-137, Feb. 2006.

[3] C. I. C. Lin, F.-Y. Kuo, and M. D. Myers, "Extending ICT4D Studies: The Value of Critical Research," MIS Quarterly, vol. 39, no. 3, pp. 697-712, 2015.

[4] R. Heeks, "Information Systems and Developing Countries: Failure, Success, and Local Improvisations," The Information Society, vol. 18, no. 2, pp. 101-112, 2002.

[5] R. Heeks, M. Amalia, K. Robert, and N. Shah, "Inclusive Innovation: Definition, Conceptualisation And Future Research Priorities," Development Informatics Working Paper Series, vol. Paper No. 53, 2013.

[6] J. L. Zittrain, The Future of the Internet and How to Stop It. New Haven, United States: Yale University Press, 2008.

[7] O. Hanseth and K. Lyytinen, "Design Theory for Dynamic Complexity in Information Infrastructures: The Case of Building Internet," J Inf technol, vol. 25, no. 1, pp. 1-19, Mar. 2010.

[8] M. Halme, S. Lindeman, and P. Linna, "Innovation for Inclusive Business: Intrapreneurial Bricolage in Multinational Corporations," Journal of Management Studies, vol. 49, no. 4, pp. 743-784, Jun. 2012.

[9] G. George, A. M. McGahan, and J. Prabhu, "Innovation for Inclusive Growth: Towards a Theoretical Framework and a Research Agenda," Journal of Management Studies, vol. 49, no. 4, pp. 661-683, Jun. 2012.

[10] S. Masiero, "The Origins of Failure: Seeking the Causes of Design-Reality Gaps," Information Technology for Development, Feb. 2016. 
[11] M. Guth, "Innovation, Social Inclusion And Coherent Regional Development: A New Diamond for a Socially Inclusive Innovation Policy in Regions," European Planning Studies, vol. 13, no. 2, pp. 333349, Jan. 2005.

[12] J. Hall, S. Matos, L. Sheehan, and B. Silvestre, "Entrepreneurship and Innovation at the Base of the Pyramid: A Recipe for Inclusive Growth or Social Exclusion?," Journal of Management Studies, vol. 49, no. 4, pp. 785-812, Jun. 2012.

[13] R. U. Mendoza and N. Thelen, "Innovations to Make Markets More Inclusive for the Poor," Development Policy Review, vol. 26, no. 4, pp. 427-458, Jul. 2008.

[14] L. Trojer, B. Rydhagen, and T. Kjellqvistt, "Inclusive innovation processes - experiences from Uganda and Tanzania," African Journal of Science, Technology, Innovation and Development, vol. 6, no. 5, pp. 425438, Sep. 2014.

[15] J. Chataway, R. Hanlin, and R. Kaplinsky, "Inclusive Innovation: An Architecture for Policy Development," Innovation and Development, vol. 4, no. 1, pp. 33-54, Jan. 2014.

[16] E. Heiskanen, S. Hyysalo, T. Kotro, and P. Repo, "Constructing innovative users and user-inclusive innovation communities," Technology Analysis \& Strategic Management, vol. 22, no. 4, pp. 495-511, May 2010.

[17] C. K. Prahalad, The Fortune at the Bottom of the Pyramid. Upper Saddle River, NJ, United States: Pearson Prentice Hall, 2005.

[18] T. Papaioannou, "How inclusive can innovation and development be in the twenty-first century?," Innovation and Development, vol. 4, no. 2, pp. 187 202, Jul. 2014.

[19] S. Cozzens and J. Sutz, "Innovation in Informal Settings - a Research Agenda," IDRC, Ottawa, 2012.

[20] C. Foster and R. Heeks, "Nurturing User-Producer Interaction: Inclusive Innovation Flows in a LowIncome Mobile Phone Market," Innovation and Development, vol. 4, no. 2, pp. 221-237, Jul. 2014.

[21] B.-Å. Lundvall, "Innovation as an Interactive Process - From User Producer Interaction to National systems of Innovation," in Technical Change and Economic Theory, G. Dosi, C. Freeman, R. Nelson, G. Silverberg, and L. Soete, Eds. London: Pinter Publishers, 1988.

[22] E. von Hippel, Democratizing Innovation. Cambridge, MA, US: MIT Press, 2005

[23] K. Swaans, B. Boogaard, R. Bendapudi, H. Taye, S. Hendrickx, and L. Klerkx, "Operationalizing Inclusive Innovation: Lessons from Innovation Platforms in Livestock Value Chains in India and Mozambique," Innovation and Development, vol. 4, no. 2, pp. 239257, Jul. 2014.
[24] R. Narsalay, L. Pongeluppe, and D. Light, "The Hidden Pitfalls of Inclusive Innovation (SSIR), , Stanford Social Innovation Review, vol. 13, no. 1, 2015.

[25] A. G. Karnani, "Romanticizing the Poor Harms the Poor," Social Science Research Network, Rochester, NY, SSRN Scholarly Paper ID 1008333, Oct. 2007.

[26] E. Kraemer-Mbula and W. Wamae, "Adapting the Innovation Systems Framework to Sub-Saharan Africa," in Innovation and the Development Agenda, Organisation for Economic Co-operation and Development, 2010, pp. 65-90.

[27] M. Müller, "The Political Dynamics of the Informal Sector in Tanzania," 2005

[28] G. Ranis and F. Stewart, "V-Goods and the Role of the Urban Informal Sector in Development,"

Economic Development and Cultural Change, vol. 47, no. 2, pp. 259-288, 1999.

[29] K. Willis, Theories and Practices of Development Taylor \& Francis, 2011

[30] J. A. Schumpeter, The Theory of Economic Development: An Inquiry Into Profits, Capital, Credit, Interest, and the Business Cycle. Transaction Publishers, 1934

[31] D. Tilson, K. Lyytinen, and C. Sørensen, "Research Commentary-Digital Infrastructures: The Missing IS Research Agenda," Information Systems Research, vol. 21, no. 4, pp. 748-759, Nov. 2010.

[32] D. E. Bailey, P. M. Leonardi, and S. R. Barley, "The Lure of the Virtual," Organization Science, vol. 23, no. 5, pp. 1485-1504, Dec. 2011

[33] E. von Hippel and R. Katz, "Shifting Innovation to Users via Toolkits," Management Science, vol. 48, no. 7, pp. 821-833, Jul. 2002.

[34] T. G. Karippacheril, F. Nikayin, M. De Reuver, and H. Bouwman, "Serving the Poor: Multisided Mobile Service Platforms, Openness, Competition, Collaboration and the Struggle for Leadership," Telecommun. Policy, vol. 37, no. 1, pp. 24-34, Feb. 2013.

[35] World Economic Forum, "The 9 countries with the most entrepreneurs," World Economic Forum. [Online]. Available: https://www.weforum.org/agenda/2015/06/the-9countries-with-the-most-entrepreneurs/. [Accessed: 30-Aug-2016]

[36] Makerere University, "Makerere University Undergraduate Fees Structure 2015/2016.” Makerere University, 2015.

[37] WorldBank, "Country Data Uganda.” 2014. 